\title{
CONDIÇÕES DE PRODUÇÃO VOCAL DE PROFESSORES DE DEFICIENTES AUDITIVOS
}

\author{
Quality of voice production in teachers of the hearing impaired
}

\author{
Léslie Piccolotto Ferreira ${ }^{(1)}$, Patrícia Helena Benedetti ${ }^{(2)}$
}

\begin{abstract}
RESUMO
Objetivo: conhecer as condições de produção vocal de professores de alunos surdos, das seis Escolas Municipais de Ensino Especial de São Paulo. Métodos: oitenta professores responderam o questionário proposto por Ferreira et al. (2003). Os dados do grupo que se auto-definiu como tendo, no passado ou no presente, alteração vocal foram cruzados com os do grupo que não fez tal referência (Teste de Correlação de Sperman). Resultados: a população estudada na sua totalidade do gênero feminino e com nível superior completo, com média de idade de 37 anos, considera, na sua maioria, o ambiente de trabalho moderado; está satisfeita com o próprio desempenho na escola; e refere autonomia no planejamento das aulas. Quanto à questão da violência nas escolas, aparece com mais freqüência indisciplina em sala de aula, brigas e problemas com drogas Quanto aos riscos ambientais, mais da metade considera a acústica satisfatória, embora alguns considerem o local ruidoso e com poeira. Quanto aos aspectos gerais de saúde, os professores fazem referência em maior número à dor de cabeça e ansiedade. A maior parte das professoras não fuma, nem consome bebidas alcoólicas e (24) $30 \%$ relataram que tem ou tiveram alteração na voz. A maioria percebeu a alteração na voz há menos de dois anos e de forma insidiosa, atribuindo sua causa ao uso intensivo da voz ou pela presença de alergia. Conclusão: as condições de produção vocal das professoras pesquisadas são semelhantes às encontradas entre professores de alunos ouvintes, porém, apenas $30 \%$ fizeram referência à alteração de voz.
\end{abstract}

DESCRITORES: Voz; Distúrbios da Voz; Docentes; Epidemiologia; Fatores de Risco

\section{INTRODUÇÃO}

Dentre os diversos profissionais, o professor é, pelo uso freqüente e muitas vezes inadequado da voz, o que aparece em maior número como sujeito de várias pesquisas realizadas pelo fonoaudiólogo no Brasil ${ }^{1}$.

O professor também se tornou tema de discussão nos "Seminários de Voz" realizados pelo Grupo de Tra-

(1) Fonoaudióloga, Professora Titular do Departamento de Fundamentos da Fonoaudiologia da Pontifícia Universidade Católica de São Paulo; Coordenadora e Docente do Curso de Especialização em Fonoaoudiologia - Voz Coordenadoria Geral de Especialização, Aperfeiçoamento e Extensão da Pontifícia Universidade Católica de São Paulo; Doutora em Distúrbios da Comunicação Humana pela Universidade Federal de São Paulo.

(2) Fonoaudióloga da Clínica Centro de Desenvolvimento Integrado - São Caetano do Sul; Pedagoga; Especialista em Voz. balho em Voz da Pontifícia Universidade Católica - SP (GT - Voz/PUC - SP, hoje denominado Laboratório de Voz - LaborVox), que desde 1997, vem discutindo as questões do distúrbio de voz relacionado ao trabalho. Em decorrência dessas discussões foi elaborado um questionário que vem sendo utilizado com diferentes professores, em São Paulo e em outros Estados, e a porcentagem daqueles que se auto definem como tendo, no presente ou passado, queixas relacionadas à voz, tem variado entre $54 \%$ a $79,6 \%{ }^{2-7}$.

Situação semelhante é encontrada na literatura internacional, que evidencia a presença de alterações decorrentes de problemas funcionais em professores 8-12. Outras pesquisas ao compararem a ocorrência de sintomas presentes em professores e enfermeiras ${ }^{13}$, professores e outros profissionais ${ }^{14,15}$, além de professores em formação e em exercício ${ }^{16}$, mostram sempre valores maiores a favor dos professores.

Cada vez mais as pesquisas evidenciam a relação de fatores ambientais e organizacionais do trabalho, 
que atuam como fatores de risco para o desenvolvimento de um distúrbio vocal. A legislação atual proposta pela Occupational Health and Safety (OSH), na União Européia, afirma que a compreensão dos problemas de saúde relacionados ao trabalho deve partir da observação da interação entre o trabalhador, o ambiente e as condições de seu posto de trabalho ${ }^{17}$.

Por outro lado, embora o número de pesquisas efetuadas com professores seja extenso, não consta na literatura uma que tenha tido como sujeito o professor que ministra aulas para crianças ou adolescentes deficientes auditivos. Ao pesquisar as condições de produção desse professor pode-se dimensionar a importância do uso da voz em contraponto com a função de ser professor, considerando que esses professores utilizam bem menos a voz, por se comunicarem com seus alunos por meio de sinais ${ }^{18,19}$.

Portanto, o presente trabalho tem como objetivo, por meio da aplicação de questionário, conhecer as condições de produção vocal de professores de alunos surdos, das seis Escolas Municipais de Ensino Especial de São Paulo (EMEE).

\section{MÉTODOS}

Para a seleção dos sujeitos, foi solicitada autorização para realização da pesquisa ao Secretário Municipal de Educação e a seguir foram visitadas as seis Escolas Municipais de Ensino Especial (a saber: EMEE Helen Keller, EMEE Madre Lucie Bray, EMEE Prof. Mário Pereira Bicudo, EMEE Prof ${ }^{a}$ Vera Lúcia Aparecida Ribeiro, EMEE Anne Sullivan e EMEE Prof $^{a}$ Neusa Basseto) e entregues 179 questionários, referentes ao número total do corpo docente nessas escolas.

O questionário, composto por 87 questões foi o mesmo proposto e aplicado em pesquisa realizada com professores da Prefeitura Municipal de São Pau$10^{7}$ e aborda questões relacionadas a dados pessoais, situação funcional (pesquisando os chamados riscos ocupacionais), aspectos vocais, aspectos de saúde geral, hábitos, antecedentes familiares e ambientes de lazer.

Depois da assinatura do termo de Consentimento, os professores responderam ao questionário, que foram devolvidos 20 dias após terem sido entregues. Dos 179 questionários enviados, retornaram 80 (44,7\% do total).

Esta pesquisa, de caráter descritivo, foi aprovada pela Comissão de Ética da Pontifícia Universidade de São Paulo-PUC-SP, sob o no. 0093/2003.

Os dados foram inicialmente tabulados e analisados considerando número absoluto e percentual. $A$ análise estatística permitiu ainda a aplicação do Teste de Correlação de Spearman (com $\mathrm{p} \leq 0.05)$ em que o grupo que se auto definiu como tendo, no presente ou no passado, alteração de voz foi comparado ao que não fez tal referência.

\section{RESULTADOS}

A população estudada, 80 professores, pode ser caracterizada como sendo na sua totalidade do gênero feminino e com nível superior completo; desses, 11 (13,75\%) citaram terem feito habilitação específica para lecionar para deficientes auditivos (Educação dos Deficientes da Áudio-Comunicação EDAC), curso ministrado no último ano de Pedagogia, em São Paulo, na Pontifícia Universidade Católica de São Paulo (PUC - SP) e nas Faculdades Metropolitanas Unidas (FMU). A média de idade registrada foi de 37 anos, e 55 (77,4\%) delas encontravam-se acima de 31 anos. Dentre as pesquisadas, $52(65,8 \%)$ atuam há mais de 10 anos, tendo trabaIhado em até cinco escolas $66(82,5 \%)$ e, atualmente, apenas na EMEE 51 (63,8\%) (Tabela 1).

Quanto à situação funcional, a maior parte dos professores $73(91,3 \%)$ leciona, em maior número $79(98,8 \%)$ no ensino fundamental, como efetivos 59 $(73,7 \%)$. A faixa etária dos alunos varia de cinco a 30 anos, e um pouco mais da metade leciona para alunos de idade entre 11 e 20 anos 37 (54,4\%). Há tendência de menor número de alunos por sala (de oito a dez), e o maior registro foi de professores com dez alunos 29 (40,3\%) em sala, atuando em período maior que 20 horas semanais 42 (60,9\%) (Tabela 2$)$.

Quanto aos aspectos do ambiente, mais da metade considera o ambiente de trabalho moderado 50 $(62,5 \%)$ e $22(27,5 \%)$, calmo. Todas 80 (100\%) têm bom relacionamento com a direção da escola, com os colegas de trabalho, com os alunos e com os pais. Estão satisfeitos com o próprio desempenho na escola 76 (95\%), considerando o trabalho nem monótono 77 (96,3\%) nem repetitivo 66 (82,5\%) e referem autonomia no planejamento das aulas 78 $(97,5 \%)$, sem fiscalização constante quanto ao seu desempenho 47 (58,8\%). Quanto ao ritmo de trabaIho, boa parte dos participantes considera o mesmo moderado 65 (81,3\%), embora sem tempo de desenvolver todas as suas atividades na escola 58 (72,5\%), necessitando complementar as atividades fora do trabalho $65(81,3 \%)$, levando-as para terminar em casa $66(82,5 \%)$. Boa parte dos entrevistados diz haver comprometimento dos funcionários com a manutenção e organização da escola 49 (61,3\%). Quanto ao material de trabalho, muitas afirmam serem adequados $49(61,3 \%)$, embora nem sempre suficiente 43 (53,8\%). Quanto à questão da violência nas escolas, o que aparece com mais freqüência é indisciplina em sala de aula $26(33,3 \%)$, brigas $21(26,9 \%)$ e problemas com drogas 15 (19\%) (Tabela 3)

Nas questões relacionadas aos riscos ambientais, boa parte dos professores considera a acústica

Rev CEFAC, São Paulo, v.9, n.1, 79-89, jan-mar, 2007 
satisfatória 52 (65\%), embora alguns considerem o local ruidoso 43 (53,8\%), afirmando vir o ruído da rua 32 (40\%). Revelam não haver umidade 70 (87,5\%), nem presença de fumaça $78(97,5 \%)$ e a temperatura 58 (72,5\%), assim como a iluminação 73 (91,3\%) são adequadas. Mais da metade dos professores afirma haver poeira no local 41 (51,3\%), e quando fazem referência à limpeza da escola, dizem que na mesma não é utilizado produto químico irritativo 53 (66,3\%). (Tabela 4)

Quanto aos aspectos gerais de saúde, os professores fazem referência em maior número a: dor de cabeça $36(45 \%)$, ansiedade $28(35 \%)$, alergia 26 $(32,5 \%)$, problema de coluna $23(28,8 \%)$, ganho de peso $23(28,8 \%)$, dor no corpo $18(22,5 \%)$, doenças das vias respiratórias $14(17,5 \%)$, resfriados freqüentes $13(16,3 \%)$, azia $13(16,3 \%)$, gastrite $12(15 \%)$ e depressão oito, (10\%). Quanto à dentição, 60 (75\%) deles apresentam a mesma completa. Dentre as queixas relacionadas à audição, $17(21,3 \%)$ citam incômodos a sons ou ruídos. Quanto ao ciclo menstrual, boa parte dos participantes afirma ter um ciclo regular 58 (72,5\%) e tensão pré-menstrual 42 (52,5\%). Quase metade dos pesquisados, tomam medicamentos $34(42,5 \%)$ de forma regular $17(48,6 \%)$ e os remédios mais citados foram os relacionados a hormônios, medicamentos para hipotireoidismo e vitaminas. (Tabela 5).

A maior parte das professoras não fuma 75 (93,8\%) e nunca fumaram 58 (72,5\%), nem consomem bebidas alcoólicas $66(82,5 \%)$ e entre os que o fazem 14 $(17,5 \%)$ a ingestão corresponde a quatro doses por semana. Quanto aos hábitos alimentares, afirmam mastigar dos dois lados $69(86,3 \%)$, evitando mais os alimentos gordurosos 44 (55\%) e em seguida os condimentados 34 (42,5\%). Nenhum professor evita derivados do leite. Poucos referem estalos ao abrir a boca dez (12,5\%), e mais da metade faz a última refeição mais de uma hora antes de dormir 46 (58,2\%). A quantidade de refeições por dia varia entre uma e seis, sendo que quase metade delas faz três refeições $30(44,1 \%)$. Alimentam-se em horários regulares $61(76,3 \%)$, bebem líquidos durante o dia 65 $(81,3 \%)$, e geralmente mais da metade delas, um litro 44 (55\%). Preferem beber o líquido na temperatura natural $70(87,5 \%)$ e boa parte deles costuma beber água quando está usando a voz 54 (67,5\%). Quanto aos hábitos vocais, um pouco mais da metade deles fala muito 41 (51,3\%), e em lugares abertos 31 $(38,8 \%)$. Parte deles procura poupar a voz entre os períodos 36 (45\%) e poucos realizam outras atividades em que necessitam usar a voz dez (12,5\%) e dentre essas algumas cantam na igreja seis (7,5\%); fazem leituras públicas, quatro $(5 \%)$ e cantam em coral, quatro (5\%). Quanto à postura durante o uso da voz, todos falam em pé e boa parte também fala sentado 72 (90\%). Quanto ao sono, quase metade deles dorme em média seis horas 39 (48,8\%) e refere acordar descansado 36 (45\%). (Tabela 6).

Dos professores pesquisados apenas um pouco menos da metade afirma ter recebido informações sobre cuidados com a voz durante a formação 37 $(46,2 \%)$, e 24 (30\%) relataram que tem ou tiveram alteração na voz, sendo que 20 (83,3\%) dentre esses, realizaram tratamento especializado, momento em que mais da metade necessitou de medicamento 13 (54,2\%). Percebem a alteração na voz há menos de dois anos $14(58,4 \%)$ e de forma insidiosa 12 $(52,2 \%)$. Na opinião deles a causa de tal problema está relacionada ao uso intensivo da voz 11 (45,8\%) ou pela presença de alergia, 10 (41,7\%). Um pouco mais da metade, dos que fizeram referência à alteração, consideram a mesma de grau leve e estável 13 $(54,2 \%)$. Das sensações percebidas sobre a voz ao longo do dia, os professores dizem estar roucos pela manhã, com melhora durante o dia, nove (37,5\%). Sobre os sintomas vocais, referiram em maior número, cansaço ao falar, sete $(29,2 \%)$ e rouquidão, cinco $(20,8 \%)$ e quanto às sensações na garganta, presença de pigarro 15 (62,5\%), garganta seca $11(45,8 \%)$ e tosse com catarro, seis (25\%). Apesar do relato desses sintomas, a maioria dos pesquisados diz estar satisfeito com a voz 21 (87,5\%). (Tabela 7).

Quando o grupo dos participantes que se autodefiniu como tendo alteração de voz no presente ou no passado foi comparado ao grupo que não fez tal referência, foi constatada diferença estatisticamente significante quanto aos seguintes aspectos: SITUAÇÃO FUNCIONAL, referente à faixa etária dos alunos (alteração vocal em maior número entre as professoras que ministram aula para alunos de faixa etária menor ( $p=0,029)$; ERGONÔMICOS, referentes à violência nas escolas (manifestações de racismo $(p=0,009)$, roubo por alunos de fora da escola $(p=0,018)$, e roubo de material da escola $(p=0,034)$; FísICOS, referentes a presença de umidade $(p=0,030)$; e a presença de poeira $(p=0,023)$; SAÚ$\mathrm{DE}$, referente a dor de cabeça $(p=0,011)$, depressão $(p=0,004)$, uso de medicamentos $(p<0,001)$, estar na menopausa $(p=0,043)$ e ciclo menstrual regular $(p=0,017)$. 
Tabela 1 - Distribuição dos professores quanto ao gênero, idade, estado civil, escolaridade, tempo de magistério, número de escolas em que trabalhou durante a carreira e número de escolas que trabalha atualmente

\begin{tabular}{|c|c|c|c|}
\hline Variáveis & & $\mathrm{N}$ & $\%$ \\
\hline Gênero & Feminino & 80 & 100,0 \\
\hline \multirow[t]{4}{*}{ Idade $^{1}$} & 20 a 30 & 16 & 22,6 \\
\hline & 31 a 40 & 34 & 47,9 \\
\hline & 41 a 50 & 15 & 21,1 \\
\hline & $>50$ & 06 & 8,5 \\
\hline \multirow[t]{3}{*}{ Estado civil $^{2}$} & Solteira & 27 & 34,2 \\
\hline & Casada & 46 & 58.2 \\
\hline & separada ou divorciada & 06 & 7,6 \\
\hline \multirow[t]{2}{*}{ Escolaridade } & superior completo & 80 & 100,0 \\
\hline & Outro superior em curso & 02 & 2,5 \\
\hline \multirow[t]{3}{*}{ Tempo de magistério ${ }^{3}$} & 1 a 10 anos & 27 & 34,2 \\
\hline & 11 a 20 anos & 42 & 53,1 \\
\hline & mais de 20 anos & 10 & 12,8 \\
\hline \multirow[t]{2}{*}{ Trabalhou no passado } & 1 a 5 escolas & 66 & 82,5 \\
\hline & mais de 5 escolas & 14 & 17,6 \\
\hline \multirow[t]{3}{*}{ Trabalha atualmente } & 1 escola & 51 & 63,8 \\
\hline & 2 escolas & 28 & 35,0 \\
\hline & 3 escolas & 01 & 1,3 \\
\hline
\end{tabular}

$\mathrm{N}$ = Número de participantes

${ }^{1} 9$ participantes não responderam esta questão ${ }^{2} 1$ participante não respondeu esta questão

${ }^{3} 1$ participante não respondeu esta questão

Tabela 2 - Distribuição dos professores quanto à situação funcional

\begin{tabular}{|c|c|c|c|c|}
\hline Variáveis & & $\mathrm{N}$ & $\%$ & Valor de $p$ \\
\hline \multirow[t]{3}{*}{ escola que atua $^{1}$} & educação infantil & 49 & 61,3 & \\
\hline & ensino fundamental & 79 & 98,8 & \\
\hline & ensino médio & 01 & 1,3 & \\
\hline \multirow[t]{3}{*}{ vínculo com a escola } & professor efetivo & 59 & 73,7 & \\
\hline & professor substituto & 04 & 5,0 & \\
\hline & outros & 17 & 29,3 & \\
\hline \multirow{5}{*}{$\begin{array}{l}\text { atividades que } \\
\text { desempenha na } \\
\text { escola }\end{array}$} & leciona & 73 & 91,3 & \\
\hline & trabalho administrativo & 09 & 11,3 & \\
\hline & atende público & 03 & 3,8 & \\
\hline & planejamento pedagógico & 03 & 3,8 & \\
\hline & sala de informática & 03 & 3,8 & \\
\hline \multirow[t]{3}{*}{ faixa etária dos alunos ${ }^{3}$} & 05 a 10 anos & 19 & 28,0 & 0,029 \\
\hline & 11 a 20 anos & 37 & 54,4 & \\
\hline & 21 a 30 anos & 12 & 17,6 & \\
\hline \multirow[t]{3}{*}{ alunos por classe ${ }^{4}$} & 10 alunos & 29 & 40,3 & \\
\hline & 09 alunos & 17 & 23,6 & \\
\hline & 08 alunos & 12 & 16,7 & \\
\hline horas de trabalho por ${ }^{5}$ & 10 a 20 horas & 27 & 33,8 & \\
\hline \multirow[t]{2}{*}{ Semana } & 21 a 30 horas & 31 & 38,8 & \\
\hline & 31 a 40 horas & 11 & 13,8 & \\
\hline
\end{tabular}

$\mathrm{N}$ = Número de participantes

Teste de Correlação de Spearman $(\mathrm{p}<0,05)$

${ }^{4} 01$ participante não respondeu esta questão ${ }^{5}$ Esta pergunta possibilita assinalar mais de uma alternativa

${ }^{6} 12$ participantes não responderam esta questão ${ }^{7} 22$ participantes não responderam esta questão

811 participantes não responderam esta questão 
Tabela 3 - Distribuição dos professores quanto à presença dos riscos ergonômicos nas escolas

\begin{tabular}{|c|c|c|c|c|}
\hline Variáveis & & $\mathrm{N}$ & $\%$ & Valor de $p$ \\
\hline \multirow[t]{3}{*}{ Ambiente de trabalho ${ }^{9}$} & Calmo & 22 & 27,5 & \\
\hline & Moderado & 50 & 62,5 & \\
\hline & Estressante & 04 & 5,0 & \\
\hline \multirow{7}{*}{$\begin{array}{l}\text { autonomia no planejamento } \\
\text { da disciplina } \\
\text { fiscalização constante do } \\
\text { desempenho } \\
\text { ritmo de trabalho }{ }^{10}\end{array}$} & $\operatorname{sim}$ & 78 & 97,5 & \\
\hline & não & 02 & 2,5 & \\
\hline & $\operatorname{sim}$ & 33 & 41,3 & \\
\hline & não & 47 & 58,8 & \\
\hline & lento & 03 & 3,8 & \\
\hline & moderado & 65 & 81,3 & \\
\hline & estressante & 09 & 11,3 & \\
\hline \multirow{4}{*}{$\begin{array}{l}\text { tempo para desenvolver as } \\
\text { atividades na escola } \\
\text { leva trabalho para casa }\end{array}$} & $\operatorname{sim}$ & 22 & 27,5 & \\
\hline & não & 58 & 72,5 & \\
\hline & $\operatorname{sim}$ & 66 & 82,5 & \\
\hline & não & 14 & 17,5 & \\
\hline \multicolumn{5}{|l|}{ comprometimento dos } \\
\hline funcionários na manutenção e & $\operatorname{sim}$ & 49 & 61,3 & \\
\hline \multirow[t]{2}{*}{ organização } & não & 31 & 45,0 & \\
\hline & $\operatorname{sim}$ & 49 & 61,3 & \\
\hline material de trabalho adequado & não & 31 & 38,7 & \\
\hline \multirow[t]{2}{*}{ material de trabalho suficiente } & $\operatorname{sim}$ & 37 & 46,2 & \\
\hline & não & 43 & 53,8 & \\
\hline \multirow{4}{*}{$\begin{array}{l}\text { complementam atividades } \\
\text { fora do período de trabalho } \\
\text { satisfação no desempenho da } \\
\text { Função }\end{array}$} & Sim & 65 & 81,3 & \\
\hline & Não & 15 & 18,7 & \\
\hline & Sim & 76 & 95,0 & \\
\hline & Não & 04 & 5,0 & \\
\hline \multirow[t]{2}{*}{ Trabalho monótono } & Sim & 03 & 3,8 & \\
\hline & Não & 77 & 96,3 & \\
\hline \multirow[t]{2}{*}{ Trabalho repetitivo } & Sim & 14 & 17,5 & \\
\hline & Não & 66 & 82,5 & \\
\hline \multirow[t]{6}{*}{ situações de violência ${ }^{11}$} & indisciplina em sala de aula & 26 & 33,3 & \\
\hline & Brigas & 21 & 26,9 & \\
\hline & problemas de drogas & 15 & 19,0 & \\
\hline & roubo de material da escola & 05 & 6,3 & 0,034 \\
\hline & roubos por alunos de fora & 01 & 1,3 & 0,018 \\
\hline & manifestações de racismo & 01 & 1,3 & 0,009 \\
\hline
\end{tabular}

$\mathrm{N}$ = Número de participantes

Teste de Correlação de Spearman $(p \leq 0,05)$

${ }^{9} 04$ participantes assinalaram mais de uma resposta

${ }^{10} 03$ participantes não responderam essa questão

1111 participantes não responderam essa questão 
Tabela 4 - Distribuição dos professores quanto à presença dos riscos ambientais

\begin{tabular}{lllll}
\hline \multirow{2}{*}{ Variáveis } & & $\mathrm{N}$ & $\%$ & Valor de $\mathrm{p}$ \\
\hline quanto ao ambiente $_{\text {físico da escola }}{ }^{2}$ & acústica satisfatória & 52 & 65,0 & \\
& presença de eco & 14 & 17,5 & \\
umidade & local ruidoso & 43 & 53,8 & \\
& presença & 10 & 12,5 & 0,030 \\
temperatura ambiente & ausência & 70 & 87,5 & \\
& adequada & 58 & 72,5 & \\
& muito fria & 14 & 17,5 & \\
iluminação & muito quente & 04 & 5,0 & \\
& adequada & 73 & 91,3 & \\
Poeira & inadequada & 07 & 8,8 & \\
& presença & 41 & 51,3 & 0,023 \\
& & & & \\
Fumaça & ausência & 39 & 48,7 & \\
produtos químicos irritativos & ausência & 78 & 2,5 & \\
na limpeza & & & & \\
& presença & 27 & 33,7 & \\
& ausência & 53 & 66,3 & \\
\hline
\end{tabular}

$\mathrm{N}$ = Número de participantes

Teste de Correlação de Spearman $(p<=0,05)$

${ }^{12}$ Esta pergunta possibilita assinalar mais de uma alternativa

${ }^{13}$ Esta pergunta possibilita assinalar mais de uma alternativa

Tabela 5 - Distribuição dos professores quanto aos aspectos gerais de saúde

\begin{tabular}{|c|c|c|c|c|}
\hline Variáveis & & $\mathrm{N}$ & $\%$ & Valor de $p$ \\
\hline \multirow{3}{*}{ estado geral de saúde ${ }^{14}$} & dores de cabeça & 36 & 45,0 & 0,011 \\
\hline & ansiedade & 28 & 35,0 & \\
\hline & alergias & 26 & 32,5 & \\
\hline \multirow[b]{2}{*}{ dentição completa } & & 60 & 75,0 & \\
\hline & $\begin{array}{l}\text { șm } \\
\text { não }\end{array}$ & 20 & 25,0 & \\
\hline \multirow{3}{*}{ Presença de alterações no ouvido ${ }^{15}$} & $\begin{array}{l}\text { incômodo a sons ou } \\
\text { ruídos }\end{array}$ & 17 & 21,3 & \\
\hline & alterações de audição & 06 & 7,5 & \\
\hline & tonturas/vertigens & 06 & 7,5 & \\
\hline \multirow{3}{*}{ Menstruação ${ }^{16}$} & ciclo regular & 58 & 72,5 & 0,017 \\
\hline & $\begin{array}{l}\text { tensão pré menstrual } \\
\text { (TPM) }\end{array}$ & 42 & 52,5 & \\
\hline & menopausa & 06 & 7,5 & 0,043 \\
\hline \multirow{3}{*}{ faz uso de medicamentos } & $\operatorname{sim}$ & 34 & 42,5 & 0.00 \\
\hline & não & 46 & 57.5 & \\
\hline & regularmente & 17 & 48,6 & \\
\hline
\end{tabular}

$\mathrm{N}$ = Número de participantes

Teste de Correlação de Spearman $(p<=0,05)$

${ }^{14}$ Esta pergunta possibilita assinalar mais de uma resposta

${ }^{15}$ Esta pergunta foi respondida somente pelos professores com alterações no ouvido

${ }^{16}$ Esta pergunta possibilita assinalar mais de uma resposta 
Tabela 6 - Distribuição dos professores quanto aos hábitos

\begin{tabular}{|c|c|c|c|}
\hline Variáveis & & $\mathrm{N}$ & $\%$ \\
\hline \multirow[t]{2}{*}{ Hábitos } & não fumam & 75 & 93,8 \\
\hline & não consomem bebidas alcoólicas & 66 & 82,5 \\
\hline \multirow[t]{4}{*}{ evitam algum tipo de alimento } & $\operatorname{sim}$ & 48 & 60,0 \\
\hline & gordurosos & 44 & 55,0 \\
\hline & condimentados & 34 & 42,5 \\
\hline & não & 32 & 40.0 \\
\hline \multicolumn{2}{|c|}{ alimentam -se em horários regulares } & 61 & 76,3 \\
\hline \multirow[t]{3}{*}{ última refeição } & mais de $1 \mathrm{~h}$ antes de dormir & 46 & 58,2 \\
\hline & 30 a 60 min antes de dormir & 25 & 31,6 \\
\hline & até $30 \mathrm{~min}$ antes de dormir & 8 & 10,1 \\
\hline \multirow[t]{4}{*}{ refeições diárias } & 3 refeições & 30 & 44,1 \\
\hline & 4 refeições & 13 & 19,1 \\
\hline & 2 refeições & 9 & 13,2 \\
\hline & 5 refeições & 9 & 13,2 \\
\hline \multicolumn{2}{|l|}{ bebem líquidos durante o dia } & 65 & 81,3 \\
\hline \multicolumn{2}{|c|}{ bebem líquidos durante o uso intensivo da voz } & 54 & 67,5 \\
\hline \multirow[t]{3}{*}{ hábitos vocais $^{17}$} & fala muito & 41 & 51,3 \\
\hline & poupa a voz entre os períodos & 36 & 45,0 \\
\hline & fala em lugar aberto & 31 & 38,8 \\
\hline \multirow{5}{*}{$\begin{array}{l}\text { não realizam outras atividades } \\
\text { postura durante o uso da } \mathrm{voz}^{18}\end{array}$} & que exigem o uso da voz & 70 & 87,5 \\
\hline & fala em pé & 80 & 100,0 \\
\hline & fala sentado(a) & 72 & 90,0 \\
\hline & fala abaixado(a) & 20 & 25,0 \\
\hline & fala com a cabeça virada & 20 & 25,0 \\
\hline \multirow[t]{2}{*}{ Sono } & dorme 6 hs/dia & 39 & 48,8 \\
\hline & acordam descansados & 36 & 45,0 \\
\hline
\end{tabular}

Tabela 7 - Distribuição dos professores quanto aos aspectos vocais

\begin{tabular}{|c|c|c|c|}
\hline \multicolumn{2}{|l|}{ Variáveis } & $\mathrm{N}$ & $\%$ \\
\hline \multirow{2}{*}{\multicolumn{2}{|c|}{$\begin{array}{l}\text { professores que afirmaram ter alteração vocal } \\
\text { realizaram tratamento }{ }^{19}\end{array}$}} & 24 & 30 \\
\hline & & 20 & 83,3 \\
\hline \multirow{8}{*}{ tempo que percebe a alteração } & medicamentoso & 13 & 54,2 \\
\hline & fonoterapia & 05 & 20,8 \\
\hline & cirúrgico & 02 & 8,3 \\
\hline & 0 a 6 meses & 07 & 29,2 \\
\hline & 6 meses a 1 ano & 03 & 12,5 \\
\hline & 1 a 2 anos & 04 & 16,7 \\
\hline & 2 a 4 anos & 03 & 12,5 \\
\hline & $>4$ anos & 07 & 29,2 \\
\hline \multirow[t]{3}{*}{ início do problema } & vai e volta & 13 & 54,2 \\
\hline & brusco & 07 & 29,2 \\
\hline & progressivo & 04 & 16,7 \\
\hline \multirow[t]{4}{*}{ possíveis causas da alteração ${ }^{20}$} & uso intensivo da voz & 11 & 45,8 \\
\hline & alergia & 10 & 41,7 \\
\hline & exposição ao frio & 07 & 29,2 \\
\hline & estresse & 07 & 29,2 \\
\hline \multirow[t]{3}{*}{ grau da alteração ${ }^{21}$} & leve & 13 & 54,2 \\
\hline & moderada & 07 & 29,2 \\
\hline & severa & 03 & 12,5 \\
\hline
\end{tabular}


grupos de não professores ${ }^{15,32}$. Enquanto com alunos ouvintes é a voz que favorece a construção do conhecimento ${ }^{33}$, com alunos deficientes auditivos isso ocorre por meio da língua de sinais ${ }^{19}$, fato que acarreta a ocorrência de lesão de esforço repetitivo nas mãos, conforme depoimento relatado por escrito por algumas das pesquisadas.

"Na verdade, não vejo relevância em realizar perfil vocal dos professores de surdos. Uma vez que hoje, as escolas caminham rumo a práticas bilíngües no ensino para surdos, é impossível ao professor utilizar duas línguas de natureza diferentes simultaneamente. Portanto utilizo com meus alunos "LIBRAS" e meu papel não é de enfocar a fala já que minha formação é pedagógica e não fonoaudiológica. Se meu papel é de professora preciso interagir com os alunos a fim de construir conhecimentos e esta interação não pode ocorrer dentro da língua oral, uma vez que meus alunos não tem acesso à ela. Acho talvez mais significativo levantar ocorrências de tendinite e "L.E.R." nos professores de surdos, por causa do uso prolongada das mãos na comunicação."

Essas professoras utilizam principalmente a língua de sinais para passar o conteúdo da matéria aos alunos e não fazem, dessa forma, uso intensivo da voz, embora mais da metade relate que fale muito.

Nesta pesquisa, os professores, por atuarem junto a alunos surdos, não utilizam a voz na mesma proporção que os professores de alunos ouvintes, porém os que apresentam alteração fazem referência a causas e sintomas semelhantes às encontradas em outras pesquisas $7,32,34$.

No momento de diferenciar o grupo que se autodefiniu como tendo alteração de voz do que não fez tal referência pode-se constatar aspectos gerais de saúde, como a dor de cabeça e a depressão, dados que vão na mesma direção da pesquisa realizada com professores da mesma autarquia ${ }^{7}$. Da mesma forma, nessa pesquisa ${ }^{7}$ e na apresentada aqui, a ingestão de medicamentos diferenciou o grupo de professoras que se auto-referiram com alteração de voz das demais, sendo nesta, o hormônio o medicamento mais citado. Outro dado significativo esteve presente na análise que cruzou a referência a alteração de voz e menopausa e o ciclo menstrual regular foi mais citado pelas professoras que não tem alterações na voz. As pregas vocais se tornam edematosas e a voz pode tornar-se mais grave e rouca. Com a menopausa ${ }^{35}$, e conseqüente diminuição do estrógeno, pode haver atrofia das mucosas, com arqueamento das pregas vocais e produção de voz soprosa.

Na mesma direção dos achados desta pesquisa e na desenvolvida com alunos ouvintes ${ }^{7}$ estiveram os dados referentes à violência. Ao analisar a violência escolar no Brasil ${ }^{34}$ concluiu-se que a mesma surge em decorrência de um conjunto significativo de práticas escolares inadequadas ao mesmo tempo que se configura como um dos aspectos que caracterizam a violência na sociedade contemporânea. Nesse último enfoque, parte dos trabalhos que pesquisou fazia referência a escolas situadas em áreas sob a influência do tráfico de drogas ou do crime organizado. Segundo a autora, as tensões existentes entre alunos ou entre estes e os adultos tem afetado especialmente a ação dos professores, que passam a sentir-se sob ameaça permanente, quer real ou imaginária. O medo do aluno leva o docente a uma freqüente demanda de segurança, particularmente policial, nas unidades escolares, comprometendo a qualidade da interação educativa.

Os dados encontrados nesta pesquisa, confirmam por um lado que a maior ocorrência de alteração vocal em professores de aluno ouvinte está relacionada ao uso intensivo e abusivo da voz, uma vez que os professores aqui pesquisados tem menor porcentagem de alteração. Por outro, reforçam que as condições ambientais e organizacionais, junto com as condições de saúde, também interferem na produção vocal sendo co-responsáveis pelas alterações vocais.

A inclusão de uma disciplina, na formação dos professores, referente à promoção de saúde vocal e ou prevenção de alterações vocais, advindas do uso profissional da voz, é fundamental para que haja um interesse crescente dos professores e das escolas em preservar a voz dos professores, instrumento imprescindível no contexto educacional, mesmo naqueles em que a voz não é o principal meio de comunicação. Porém os fonoaudiólogos, profissionais responsáveis por essas práticas, devem estar atentos ao fato de que não basta priorizar apenas as questões referentes à produção da voz (beber água, fazer aquecimento e desaquecimento vocal, falar em menos tempo e em menor intensidade, entre outros), mas sim entender que as questões do ambiente e organizacionais, por sua complexidade, podem estar interferindo na produção da mesma. Tais questões consideradas estressantes, aparecem em pesquisas de outras áreas ao analisarem outro tipo de sintoma, por exemplo os fisioterapeutas ao pesquisarem sobre a ocorrência de LER/DORT, alteração esta mencionada por alguns dos professores desta pesquisa ${ }^{36}$.

Um último aspecto merece destaque: a diferença constatada ao se comparar o retorno de questionários desta pesquisa (44\%), com o da realizada na mesma autarquia, porém com alunos ouvintes ${ }^{7}(91 \%)$. Certamente houve, na realização desta segunda, maior mobilização da Secretaria de Educação do Município de São Paulo, assim como da Superintendência de Educação do Município (SUPEME), interessados na época em conhecer a ocorrência de alterações vocais presentes nos professores da rede. Tal fato evidencia 
a necessidade de envolvimento de todos os atores socias para que uma pesquisa desta natureza tenha maior retorno com relação aos resultados.

\section{CONCLUSÃO}

As condições de produção vocal das professoras pesquisadas são semelhantes às encontradas entre professores de alunos ouvintes, porém, apenas um terço se auto-definiu com alteração de voz, com sintomas e prováveis causas semelhantes aos achados em pesquisas realizadas com outro tipo de professor. Quando as que fizeram referência à alteração de voz foram comparadas com as que não fizeram tal referência se diferiram significativamente nos aspectos relacionados a dar aula para alunos de faixa etária menor, estarem imersas em locais com poeira e umidade, estarem expostas a situações de violência, apresentarem problemas de saúde (mais especificamente dor de cabeça, depressão e alterações hormonais) e ingerirem medicamento (na maioria hormônios).

\begin{abstract}
Purpose: to determine voice quality in teachers of deaf students at the six Special Municipal Schools in the city of São Paulo. Methods: eighty teachers responded to a questionnaire proposed by Ferreira et al. (2003) Information on the group who stated that they currently have or have had in the past any voice alteration was cross-checked with information on the group who did not report such complaint (Spearman Correlation Test). Results: the research population, all female college graduates, with an average age of 37 , considers the workplace moderate, is satisfied with their own performance at school, and refers to autonomy in class planning. With regard to the issue of school violence, classroom indiscipline, fight, and drug problems are more often reported. With regard to environmental risks, most consider acoustics satisfactory, although some of them consider the workplace noisy and dusty. With regard to general health issues, teachers most frequently refer to headache and anxiety. Most teachers do not smoke, or drink alcoholic beverages and 30\% (24) reported that they have or have had any voice alteration and noticed the voice alteration less than two years ago and in an insidious way and probably caused by the heavy use of voice or presence of allergy. Conclusion: voice generation conditions of teachers that responded a questionnaire showed similar results as for those teachers of listening students, even so, only $30 \%$ reported voice alteration.
\end{abstract}

KEYWORDS: Voice; Voice Disorders; Faculty; Epidemiology; Risk Factors

\section{REFERÊNCIAS}

1.Simões M. A voz do professor: histórico da produção científica de fonoaudiólogos brasileiros sobre o uso da voz nessa categoria profissional. In: Ferreira LP, Oliveira SMRP, organizadores. Voz profissional: produção científica da fonoaudiologia brasileira. São Paulo: Roca; 2004.

2.SESI. Serviço Social da Indústria. Projeto Saúde Vocal. São Paulo; 2000.

3.Simões M. Prevalência de disfonia e estudo de seus fatores associados em educadoras de creche [mestrado]. São Paulo (SP): Departamento de Epidemiologia da Faculdade de Saúde Pública da Universidade de São Paulo; 2001.

4.Zanon NG. Condições de produção vocal do professor de natação [monografia]. São Paulo (SP): Pontifícia Universidade Católica; 2001.

5.Alves IAV. Perfil vocal de docentes do ensino municipal e privado da cidade de Jataí - Goiás [mestrado]. São Paulo (SP): Pontifícia Universidade Católica;2002.
6. Lima WR. Perfil vocal dos professores dos municípios de Vitória e Vila Velha. [mestrado]. São Paulo (SP): Pontifícia Universidade Católica; 2002.

7.Ferreira LP, Karmann DF, Silva EEH, Figueira S, Giannini SPP, Souza TMT. Condições de produção vocal de professores da rede do município de São Paulo. In: Rev Disturb Comun. 2003; 14(2):275-308. 8.Garcia OC, Torres RP, Shasat ADD. Disfonias ocupacionales: estudio de 70 casos. Rev Cub Med. 1986; 25:998-1009.

9.Callas M, Verhulst J, Lecoq M, Dalleas B, Seilhean M. La pathology vocale chez l'ensignant. Rev Laryngol. 1989; 110(4):397-406.

10. Sarfati J. Réadaptation vocale des enseignants. Rev Laryngol. 1989; 110(4):393-5.

11. Masuda T, Ikeda Y, Manako H, Komiyama S. Analysis of vocal abuse: fluctuations in phonation time and intensity in 4 groups of speakers. Acta Otolaryngol. 1993; 113(4):547-52.

12. Smith E, Kirchner HL, Taylor M, Hoffman H, Lemke J. Voice problems among teachers: differences by 
gender and teaching characteristics. J Voice. 1998; 12(3):328-34.

13. Sala E, Laine A, Simberg S, Pentti J, Suonpaâ J. The prevalence of voice disorders among day care center teachers compared with nurses: a questionnaire and clinical study. J Voice. 2001; 15(3) 413-23.

14. Williams NR. Occupational groups at risk of voice disorders: a review of the literature. Occup Med. 2003; 53(7):456-60.

15. Roy N, Merrill RM, Thibeault S, Parsa RA, Gray SD, Smith EM. Prevalence of voice disorders in teachers and the general population. J Speech Lang Hear Res. 2004; 47(2):281-93.

16. Yiu EML. Impact and prevention of voice problems in the teaching profession: embracing the consumer's view. J Voice. 2002; 16(2):215-28.

17. Vilkman E. Occupational safety and health aspects of voice and speech professions. Folia Phoniatr Logop. 2004; 56(4):220-53.

18. Valverde RL. Relatos de professores sobre a mudança metodológica em uma escola para deficientes auditivos [mestrado]. São Paulo (SP): Pontifícia Universidade Católica; 1992.

19. Lacerda CBF. A prática pedagógica mediada (também) pela língua de sinais: trabalhando com sujeitos surdos. Cad CEDES. 2000; 20(50):70-83.

20. Dragone MLOS, Sichirolli S, Reis R, Behlau M. O desgaste vocal do professor: um estudo longitudinal. Rev Soc Bras Fonoaudiol. 1999; 3(5):50-6.

21. Viola IC, Ferreira LP, Sene CD, Villas Boas DC, Souza SM. Avoz do professor: levantamento das publicações brasileiras. Rev Soc Bras Fonoaudiol. 2000; 5(7):36-47.

22. Silvany AM, Araújo T, Dutra F, Azi G, Alves R, Kavalkievicz C, et al. Condições de trabalho e saúde de professores da rede particular de ensino de Salvador, Bahia. Rev Baiana Saúde Públ. 2000; 24:42-6.

23. Fabron EMG. Levantamento de queixas vocais em um grupo de professores da rede estadual de ensino de Marília. In: Ferreira LP. Voz ativa: falando sobre a clínica fonoaudiológica. São Paulo: Roca; 2001.

24. Schwarz K, Cielo CA. A voz a as condições de trabalho de professores de cidades pequenas do Rio Grande do Sul. Rev Soc Bras Fonoaudiol. 2005;
10(2):83-90.

25. Hammond TH, Zhou R, Hammond EH, Pawlak A, Gray SD. The intermediate layer: a morphologic study of the elastin and hyaluronic acid constituents of normal human vocal folds. J Voice. 1997; 11(1):59-66.

26. Aldrighi JM, Hueb C, Aldrighi AP. Climatério. Rev Diag Trat. 2000; 57:209- 15.

27. Behlau M, Rehder M, Valente, O. Disfonias endócrinas. In: Behlau M. Voz: o livro do especialista. v. 2. Rio de Janeiro: Revinter; 2005. p. 52-68.

28. Servilha EAM. Consciência vocal em docentes universitários. Pró-Fono RAtual Cient. 1997; 9(2):53-61. 29. Pordeus AMJ, Palmeira CT, Pinto VCV. Inquérito de prevalência de problemas de voz em professores da Universidade de Fortaleza. Pró-Fono R Atual Cient. 1996; 8(2):15-24.

30. Wilson K. Problemas de la voz en los niños. Buenos Aires: Médica Panamericana; 1973.

31. Preciado J, Perez C, Calzada M, Preciado P. Prevalence and incidence studies of voice disorders among teaching staff of La Rioja, Spain. Clinical study: questionnaire, function vocal examination, acoustic analysis and videolaryngostroboscopy. Acta Otorrinolaringol Esp. 2005; 56(5):202-10.

32. Sliwinska-Kowalska M, Niebudek-Bogusz E, Fiszer M, Los-Spychalska T, Kotylo P, SznurowskaPrzygocka B, Modrzewska M. The prevalence and risk factors for occupational voice disorders in teachers. Folia Phoniatr Logop. 2006; 58(2):85-101. 33. Servilha EAM. Caracterização do perfil vocal em professores do terceiro grau. In: Lacerda CBF, Panhoca I. Tempo de fonoaudiologia II. Taubaté: Cabral Universitária; 1998. p. 95-117.

34. Sposito MP. Um breve balanço da pesquisa sobre violência escolar no Brasil. Educ Pesq. 2001; 27(1):87-103.

35. Cervantes O, De Biase NG. Distúrbios vocais: efeitos de medicamentos na voz. In: Ferreira LP, Costa HO. Voz ativa: falando sobre a clínica fonoaudiológica. São Paulo: Roca; 2001.

36. Verthein MAR, Minayo-Gomez C. A construção do "sujeito-doente" em LER. Hist Cienc Saúde Manguinhos. 2000; 7(2):327-45.
RECEBIDO EM: 22/08/06

ACEITO EM: 24/02/07

Endereço para correnspondência:

Rua Jesuíno Bandeira, 73

São Paulo - SP

CEP: 05048-080

Tel/fax: (11) 38752940

E-mail: leslieferreira@yahoo.com 